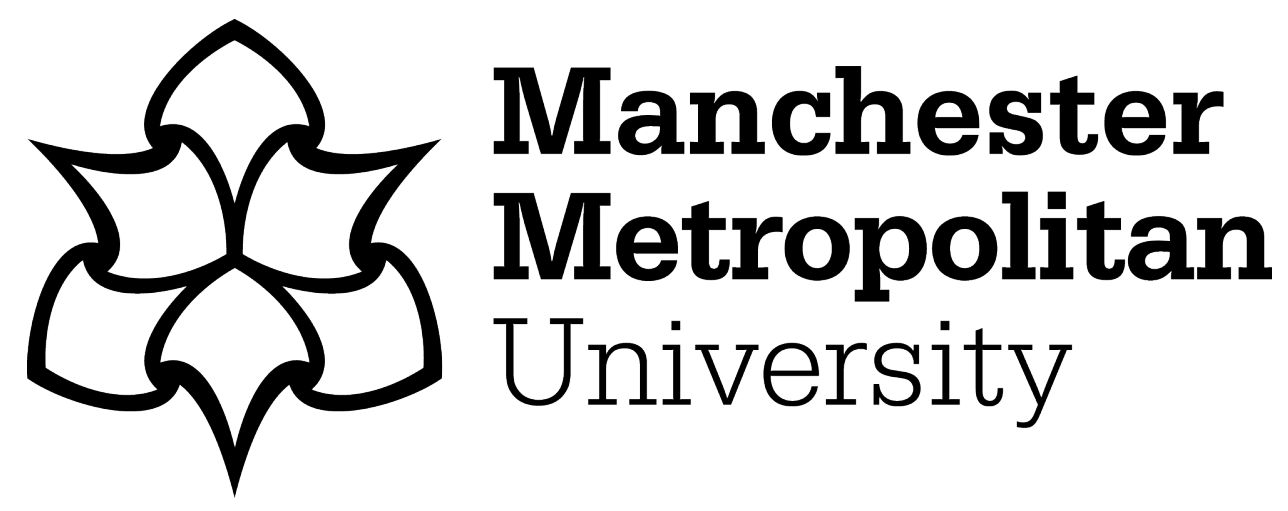

Kumar, VDA, Sharmila, S, Kumar, A, Bashir, AK, Rashid, M, Gupta, SK and Alnumay, WS (2021) A novel solution for finding postpartum haemorrhage using fuzzy neural techniques. Neural Computing and Applications. ISSN 0941-0643

Downloaded from: https://e-space.mmu.ac.uk/627681/

Version: Accepted Version

Publisher: Springer (part of Springer Nature)

DOI: https://doi.org/10.1007/s00521-020-05683-z

Please cite the published version 


\title{
A Novel Solution for Finding Postpartum Haemorrhage using Fuzzy Neural
}

\section{Techniques}

\author{
V.D. Ambeth Kumar ${ }^{1}$, S. Sharmila ${ }^{1}$, Abhishek Kumar ${ }^{2}$, A. K. Bashir ${ }^{3}$ Mamoon Rashid ${ }^{4,}$, Sachin Kumar Gupta ${ }^{5}$, \\ Waleed S. Alnumay ${ }^{6}$ \\ ${ }^{1}$ Panimalar Engineering College, Anna University, Chennai, 600123, India. \\ ${ }^{2}$ School of Computer Science \& IT, Jain (to be Deemed University), Bangalore, India \\ ${ }^{3}$ Department of Computing and Mathematics, Manchester Metropolitan University, UK. \\ ${ }^{4}$ School of Computer Science \& Engineering, Lovely Professional University, Jalandhar, India \\ ${ }^{5}$ School of Electronics \& Communication, Shri Mata Vaishno Devi University, Katra, Jammu, India. \\ ${ }^{6}$ Department of Computer Science, King Saud University, Riyadh, Saudi Arabia.
}

Correspondence*: mamoon.20574@lpu.co.in

\begin{abstract}
:
Postpartum Haemorrhage (PPH) is the loss of blood above $500 \mathrm{ml}$ during vaginal or caesarean deliveries. It is difficult to find a PPH in an earlier stage, so pregnant women are exposed to excess blood loss that make them suffer and die. Antenatal practices help in identifying risk factors, and modern technology is used to overcome the risk. Still, the morbidity rate and the mortality arise due to the unpredicted and unexpected cause. PPH is still a significant cause of maternal morbidity and mortality worldwide. The novelty of this research work is to alert medical practitioner about excessive bleeding of pregnant women during childbirth. We are proposing an automation system using wearable devices to prevent pregnant women from the PPH. These devices measure parameters like temperature, pulse rate, blood pressure, and sweat rate of pregnant women. Fuzzy Neural technique based rules are used for each parameter to predict the risk in developing PPH and to evaluate the performance of proposed system for reducing mortality and morbidity rates. Our findings of experiment is carried on metrics of HPPH (High Level Postpartum Haemorrhage), NPPH (Normal Level Postpartum Haemorrhage), MPPH (Medium Level Postpartum Haemorrhage) for 15 patients. Fuzzy output value of 1 indicates patient state with NPPH, 0 indicates patient state with HPPH and values in between 0 to 1 indicate MPPH. Based on the sensitivity of the predicted values, medical attention is taken from doctors or nurses in nearby locations using Internet of Things infrastructure.
\end{abstract}

Keywords: Fuzzy; Haemorrhage; Hysterectomy; Internet of Things; Mortality; Postpartum; Uterine Atony

\section{Introduction}

The statistical fact revealed by the World Health Organization claims that about 14 million women suffer from PPH all around the world. One of the most common causes is due to severe bleeding in a female genital tract, which may threaten life and can lead to fatal consequences. Haemorrhage is one of the main factors responsible for maternal death. It is the death caused by the rupture of the blood vessel during pregnancy. Uterine Atony is one of the prime risk factors for maternal death. In some PPH cases, they were unresponsive to medical treatments. If the uterus is not appropriately contracted, then it is Uterine Atony, where the blood vessels fled freely, and the Haemorrhage occurs. Uterus weights a little over a pound during the first week after childbirth. During the second week, it weights 11 ounces. In the fourth week, it remans close to its pre-pregnancy weight of 3.5oucnes or less. If the Uterus is not contracted, then using Uterotonic, Balloon Tamponade technique, B-Lynch suture, Hayman suture is handled.

PPH is recognized in two ways namely primary and secondary PPH. Primary PPH leads to immediate death within 24 hours of delivery with the excessive loss of $500 \mathrm{ml}$ of blood followed by child birth from the vaginal canal, whereas the secondary PPH is the excessive vaginal bleeding after the delivery and within 6 weeks of postpartum. In most of the cases, the late PPH are due to the retained products of conception and infection or both. Despite developed antenatal practices, solutions for the complete cure are still under research. A major cause for the 
recurrence and occurrence of $70 \% \mathrm{PPH}$ is because of uterine atony which is the failure of the uterus after the delivery $[1,2]$. Some other leading causes are trauma, retained placenta, placental abruption, placenta previa, multiple pregnancy and blood coagulation abnormalities [2-4]. In general, the clinical manifestation of bleeding in secondary PPH is classified into two types as external bleeding and internal bleeding as shown in Figure 1.

Internal bleeding also leads to Uterine Atony which is due to any Haemorrhage in a uterine region that causes trauma or improper delivery of the placenta. It is mainly due to active or no active bleeding $[5,6]$. The treatment for internal bleeding is handled through the technique of embolization which involves holding of the bloodstream by lodging of embolus during heavy bleeding with uterine fibroids $[5,7]$. Generally, internal iliac atony is carried out, in case of massive obstetric haemorrhage that preserves the reproduction functions and acts effectively in controlling the bleeding [8]. In worst cases, hysterectomy is performed surgically to remove the uterus $[6,9]$. The external bleeding is occurring because of poor uterus contraction which causes the blood vessel feeding into the site where the placenta is attached to continue bleeding $[10,11]$. Lower genital tract lacerations are handled during the poor contraction of the uterus after keen observation of vaginal trauma. Medical therapy includes oxytocin and ergot alkaloids, prostaglandins [10-13]. During this stage, Episiotomy (perineotomy) is the surgical incision of perineum and the postal vaginal wall to enlarge the opening for the baby to pass through. Various techniques like Uterotonic and balloon tamponade technique, B-lynch, and Hayman suture are practiced to overcome the poor contraction of the uterus $[5,14]$. Balloon tamponade technique serves as the lifesaving intervention in low resource areas where the blood transfusion and surgical facilities are not available [14]. B-lynch suture is a compression suture used in the postpartum period that mechanically compresses the atonic uterus during severe PPH $[14,15]$. Hayman suture is similar to B-lynch with a slight modification which is considered as easier, faster approach in an emergency. The techniques of balloon tamponade, B-lynch, and Hayman suture are used to present the PPH. With all these challenges, there is a strong need of automation system that will predict PPH in efficient manner.

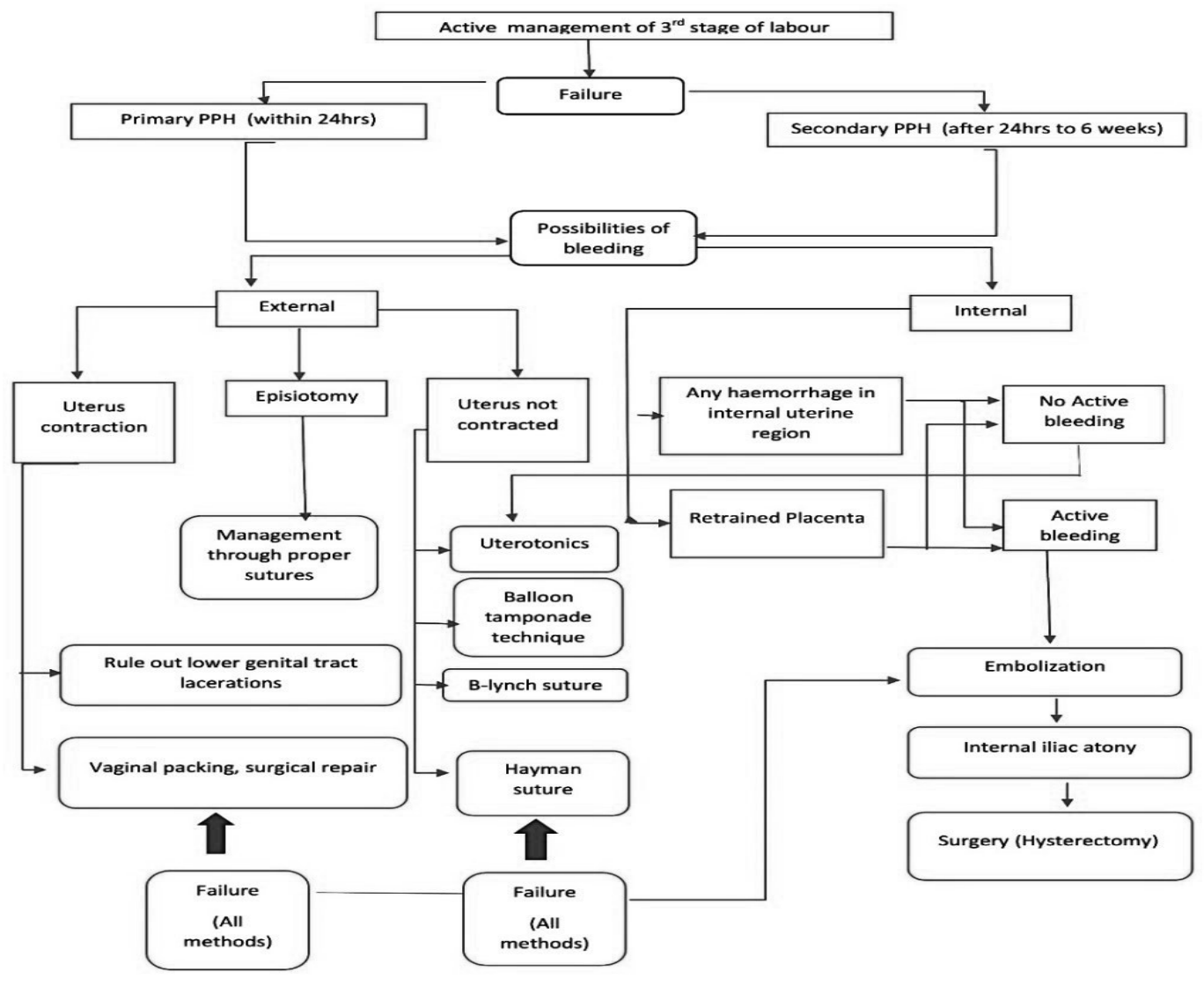

Fig. 1. Third Stage of Labour with Phases of Bleeding 
In this work, an automation system is designed and implemented to measure PPH levels in pregnant women to predict the risk involved in developing PPH. The major contributions of this paper are as follows:

1. Our work proposed an automation system using wearable devices to prevent pregnant women from the PPH by measuring parameters like temperature, pulse rate, blood pressure, and sweat rate.

2. An efficient Fuzzy Neural technique based rule algorithm is developed for input parameters of temperature, pulse rate, blood pressure, and sweat rate of pregnant women to predict the risk in developing PPH.

3. Our proposed system uses efficient IoT based alerting system to seek medical attention of medical practitioners in nearby locations for pregnant women based on the sensitivity of predicted values from fuzzy system.

The organization of paper is as follows: section 2 gives the analysis of the existing concepts, section 3 elaborately explains the prediction and identification of PPH patients, section 4 explains the implementation of a proposed neural network, section 5 implicit the evaluation and section 6 concludes the results.

\section{Literature Review}

In this section, the existing works related to PPH are discussed. Many researchers have surveyed external bleeding, saying that mortality rate occurring is $80 \%$ because of uterine atony [1], [16, 17]. The remaining is in $\mathrm{PPH}$ complications due to the retained placenta $[18,19]$. One of the effective medicines suggested by Lusia A Wetta is a magnesium sulphate that reduces about $10 \%$ occurrence of preeclampsia in women undergoing vaginal delivery [1]. However, one of the innovative solutions to treat PPH effectively is 4T's namely Tone, Tissue, Thrombin, Trauma $[10,20]$. Research works claim that tranexamic acid is also useful in treating PPH [6, 21-23]. On the other hand, improvement in treating PPH after implementing Controlled Cord Traction is possible in the third stage of labour [5].

Edwin Chandraharan- a consultant obstetrician and gynaecologist studied the management of PPH in the year 2017 and concluded that after adjustment for all potential confounders, intrapartum use of oxytocin was associated with a significantly higher risk of severe PPH [16]. A management algorithm called HAEMOSTASIS has been proposed to aid systematic and stepwise management of PPH. A randomized controlled trial showed that active management of the third stage alone reduces the incidence of primary PPH by $70 \%$ compared with physiological management alone. Based on the recent WOMAN trial, tranexamic acid is recommended in the routine management of PPH unless there are specific contra-indications. Risk factors for severe PPH: a case-control study proposed by Irene Sandven et al. in the year 2017 addressed the risk factor based on Tone (uterine atony, uterine inversion and abruption of the placenta), Tissue (retained placenta and retained parts of placenta, and abnormal placentation), Trauma (uterine rupture, birth canal trauma, and surgical trauma) and Thrombin (coagulation disorders) [24]. The article specifies all the principal risk factors for severe PPH that serve as a precaution to avoid severe PPH conditions.

Stepan Feduniw et al. has addressed the risk factor based on uterine atony and also mentioned the effective treatment for PPH [25]. Abir Saha et al. had discussed the possible Social Networking Sites (SNS) based interventions and design implications that can effectively and feasibly reduce Postpartum Depression (PPD) in women in developing countries [26]. Fan Qi et al. in the year 2018 has proposed K-Nearest Neighbour (KNN) algorithm, which is used for predicting the PPH [27]. It can contribute to the prevention and control of PPH. Radite Purwahana has revealed the purpose of multinomial logistic regression, which is used to analyze the data of mothers dying in the postpartum period based on the main variables causing maternal death [28]. Daniel Surbek have analyzed, and conclusions were made by the Swiss PBM in obstetrics working group of experts in a consensus meeting [29]. Oluwakemi Adegoke developed the Every Second Matters for Mothers and Babies by using Uterine Balloon Tamponade (ESM-UBT) device which is used to control the blood to the uterus [30, 31]. Marieke C. Punt [29] has revealed obstetric bleeding problems often occur in women with Inherited Platelet Receptor Defects (IPRD). To improve the clinical management of women-specific bleeding in IPRD, international cooperation is required, preferably on prospective studies.

Mahmoud Alalfy mentioned the usage of intrauterine misoprostol for the prevention of primary PPH which is supported by several other researches [32-34]. Another research diagnosed the uterine disease with the Mamdani Fuzzy Inference System [35]. Fuzzy Inference system is commonly used method for the detect of the disease [36]. Umi Salamah discussed the postpartum infection type using Mamdani fuzzy system [37]. João Luis Zeni Montenegro introduces a Multifaceted Model of Natural Language Generation for women in a postpartum [38]. A research has been conducted to provide some guidelines and strategies for implementing mHealth apps and services to support maternal healthcare in developing countries [39]. 
Based on the these limitations of balloon tamponade, B-lynch, and Hayman suture techniques related to PPH, the authors incorporate and proposed an automation system using wearable devices to prevent pregnant women from the PPH by measuring parameters like temperature, pulse rate, blood pressure, and sweat rate. This system uses efficient IoT based alerting system working on fuzzy neural technique to seek medical attention of medical practitioners in nearby locations for pregnant women based on the sensitivity of predicted values from fuzzy system.

\section{Proposed System}

The proposed method is to analyze the parameters (temperature, blood pressure, pulse rate and sweat rate) of women in labor ward. It has high accuracy to predict the PPH patients and has a fast training process for predicting whether the patients are affected by PPH or not. In Fig. 2, doctor provide a wearable device to pregnant women and it measure temperature, blood pressure, pulse rate and sweat rate. For PPH identification, the range of parameter value should be defined. The parameter value in the obtained data indicates the biological condition of pregnant women. This parameter also checks whether the patient's biological condition is normal or not. If parameter value exceeds from the normal level, then the pregnant women is affected by PPH.

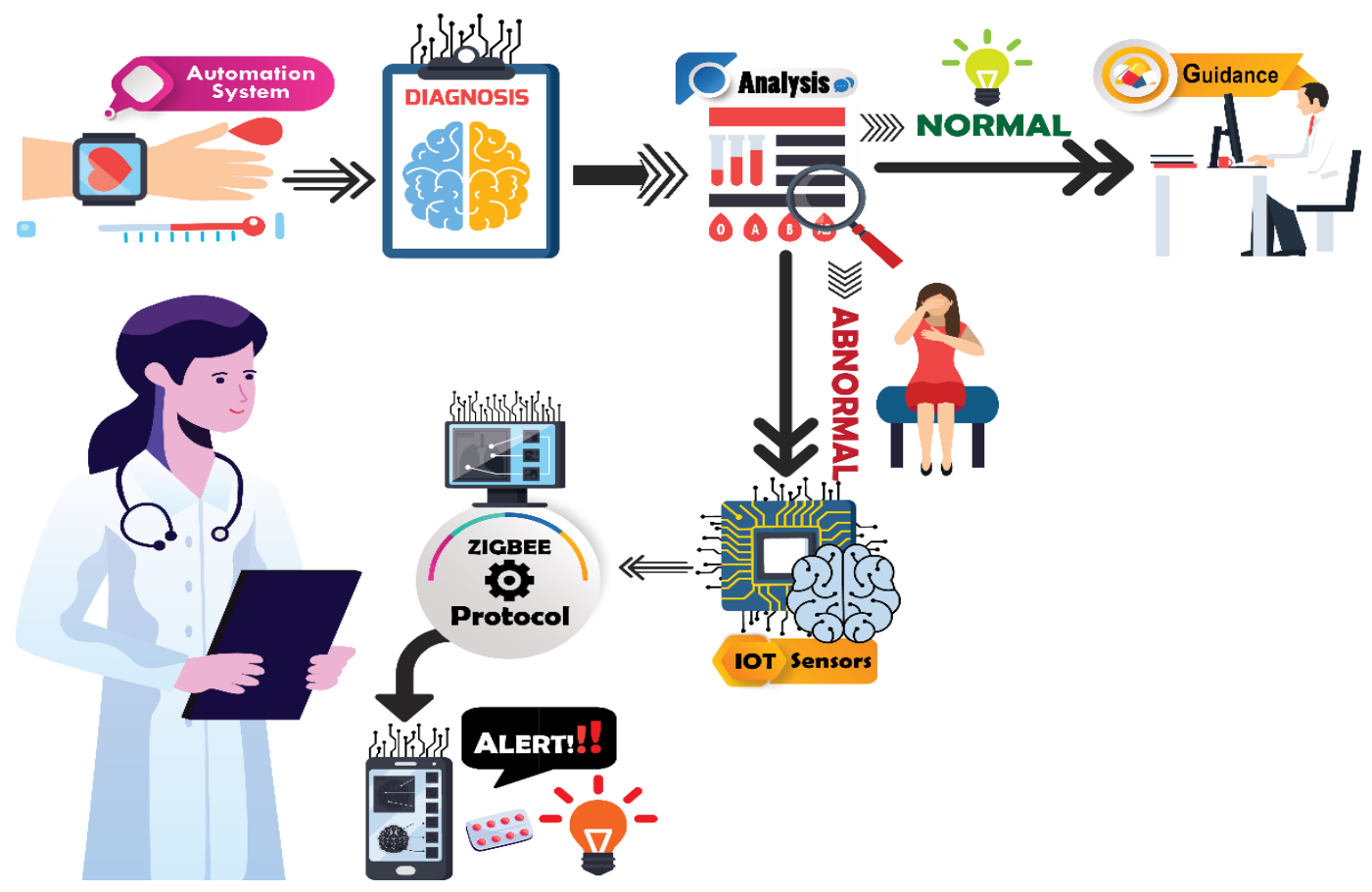

Fig. 2. Identification of PPH

\subsection{Prediction of Temperature using Fuzzy Series:}

The normal temperature of the patients is $98.6 \mathrm{~F}$. However, the temperature varies for patients who are affected by $\mathrm{PPH}$ and variation in temperature depends on the health condition of patients.

Membership Function for Temperature: $\mathrm{T}$ be a fuzzy event whose membership function is $\mu_{\mathrm{T}}(\mathrm{x})$. For $\mu_{\mathrm{T}}(\mathrm{x}) \subseteq[0$, 1], so $\mu_{\mathrm{T}}(\mathrm{x})=1$, therefore a function exists $\mu_{\mathrm{T}}(\mathrm{x})$ which satisfies the equation 1 :

$$
\mu_{T}(x)=\int_{b}^{c} \mathbf{f} \mu_{T}(x) d x=1
$$

To identify the PPH patients, we should define the membership function $\mu_{\mathrm{T}}(\mathrm{x})$ satisfying equation 2 and as shown in Fig. 3 


$$
\mu_{T}(x)=\int_{z}^{b} \frac{x-z}{b-z}+\int_{c}^{d} \frac{d-x}{d-c}
$$

\section{$\mu_{T}(\boldsymbol{x})$}

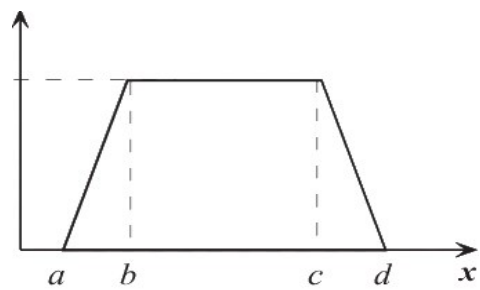

Fig. 3. Membership Function for Temperature

The membership function of pregnant women is defined by using equation 3 as

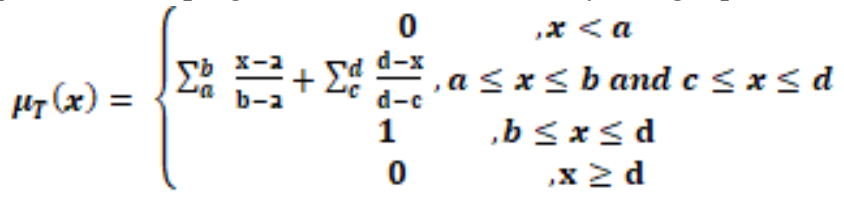

where, $\mathrm{P}=\{\mathrm{P} 1, \mathrm{P} 2 \ldots \mathrm{Pn}\}$ indicates the number of pregnant woman.

$\mathrm{x}=\{\mathrm{x} 1, \mathrm{x} 2 \ldots \mathrm{xn}\}$ be the temperatures of $\mathrm{N}$ number of patients

"a" indicates the minimum body temperature of pregnant woman which is less than $95 \mathrm{~F}$ and it indicates the patient's health is abnormal.

" $\mathrm{b}$ " denotes the starting temperature level of normal human body which is in $97.7 \mathrm{~F}$ and it indicates the patient's health condition is normal.

"c" denotes the ending temperature level of normal human body which is in $99 \mathrm{~F}$ and it is also indicates that patient's health condition is normal.

" $\mathrm{d}$ " denotes the maximum body temperature of the pregnant women which is more than $100.4 \mathrm{~F}$ and it indicates that pregnant women are affected by PPH.

The normal body temperature of human body ranges from $97.7 \mathrm{~F}$ to $99.5^{\circ} \mathrm{F}$. If the body temperature in women carrying pregnancy is in the range of $95 \mathrm{~F}$ to $97.7 \mathrm{~F}$ or $97.7 \mathrm{~F}$ to $100.4 \mathrm{~F}$, then it is treated as abnormal condition and we need to identify whether they can be affected by PPH or not.

From the temperature $\mathrm{P}$, we will initiate fuzzy rule for identifying the PPH affected patients in the form of Algorithm I.

Algorithm I - Fuzzy Rule for Temperature

\begin{tabular}{ll}
\hline INPUT: $\mathrm{P}=\{\mathrm{P} 1, \mathrm{P} 2 \ldots \mathrm{Pn}\}$ be the number of pregnant women. \\
\hline $\mathrm{x}:$ & Denote the body temperature of pregnant women. \\
$\mathrm{a}:$ & Indicate the minimum body temperature of the pregnant women. \\
$\mathrm{b}:$ & Indicate the starting temperature level of the pregnant women. \\
$\mathrm{c}:$ & Indicate the ending temperature level of the pregnant women. \\
$\mathrm{d}:$ & Indicate the maximum body temperature of the pregnant women. \\
$\mu \mathrm{T}(\mathrm{x})$ & Denotes Membership function \\
\hline OUTPUT: Identify the PPH patients based on temperature
\end{tabular}


Initialize the Membership Function

$\mu \mathrm{T}(\mathrm{x})$ is set to zero

Begin

if $(\mathrm{b} \leq \mathrm{x} \leq \mathrm{c})$ then

The Membership function $\mu_{\mathrm{T}}(\mathrm{x})$ is set to one

else if $(x<a)$ then

The Membership function $\mu_{\mathrm{T}}(\mathrm{x})$ is set to zero

else if $(\mathrm{a} \leq \mathrm{x} \leq \mathrm{b})$ and $\mathrm{c} \leq \mathrm{x} \leq \mathrm{d})$ then

The Membership function will be calculated by using $\sum_{a}^{b} \frac{x-a}{b-a}+\sum_{c}^{d} \frac{d-x}{d-c}$ else

The Membership function $\mu_{\mathrm{T}}(\mathrm{x})$ is set to 0

\section{End}
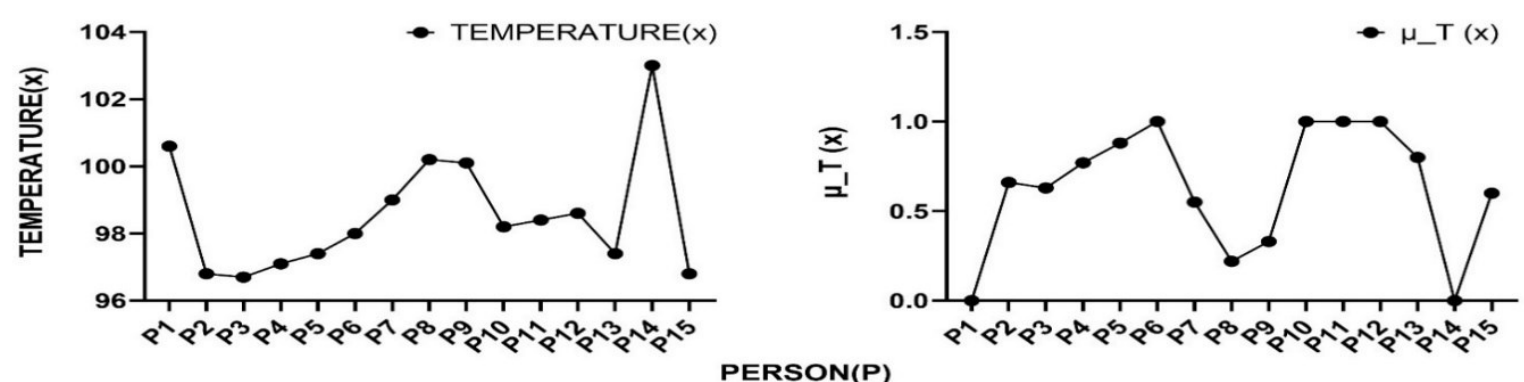

Fig. 4. Affected Patients List based on the above Membership Function

As shown in Fig.4, Persons P6, P10, P11 and P12 are not being affected by PPH because the value of their membership function for temperature is equal to 1 . However, P1 and P14 are being affected by PPH as the value of their membership function for temperature is equal to 0 . Further, remaining persons carrying membership function value for temperature between 0 and 1 are having tendency to fall in PPH and thus need medical assistance.

\subsection{Prediction of Pulse Rate using Fuzzy Series:}

For a normal person, the pulse rate is 72 beats per minute (bpm). During PPH, it will increase up to 80 or $90 \mathrm{bpm}$.

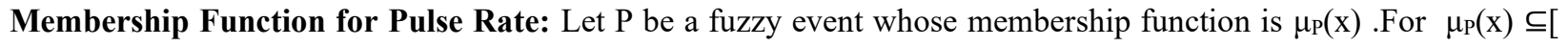
$0,1]$, so $\mu_{\mathrm{P}}(\mathrm{x})=1$, therefore a function exists $\mu_{\mathrm{P}}(\mathrm{x})$ which satisfies the equation 4 :

$$
\mu_{P}(x)=\int_{b}^{c} f \mu_{P}(x) d x=1
$$

To identify the PPH patients, we should define the membership function $\mu_{p}(x)$ satisfying equation 5:

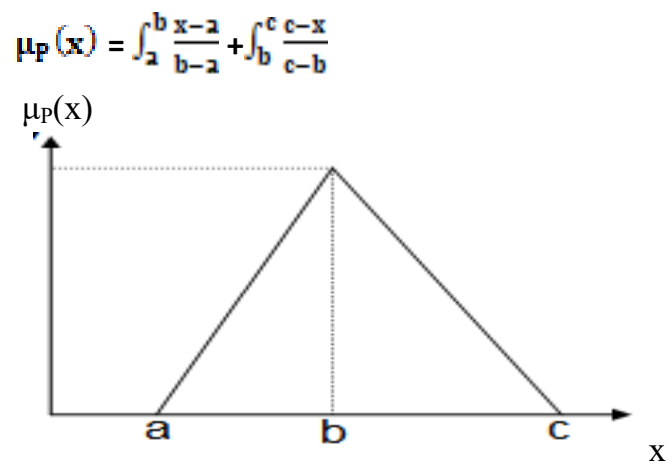

Fig. 5. Membership Function for Pulse Rate 
The membership function of pregnant women is defined by equation 6 as:

$$
\mu_{P}(x)=\left\{\begin{array}{cc}
0 & , x>c \text { and } x<a \\
\frac{x-a}{b-a} & , a \leq x \leq b \\
\frac{c-x}{c-b} & , b \leq x \leq \mathrm{c} \\
1 & , \mathrm{x}=\mathrm{b}
\end{array}\right.
$$

where, $\mathrm{P}=\{\mathrm{P} 1, \mathrm{P} 2 \ldots \mathrm{Pn}\}$ indicates the number of pregnant women.

$\mathrm{x}=\{\mathrm{x} 1, \mathrm{x} 2 \ldots \mathrm{xn}\}$ be the pulse rates of $\mathrm{N}$ number of patients

"a" denotes the minimum pulse rate of pregnant women representing the patient's condition as abnormal and thus we need to identify whether they can be affected by postpartum hemorrhage or not.

" $b$ " denotes the standard pulse rate of pregnant women and it indicates their biological condition is average.

"c" denotes the maximum pulse rate of pregnant women, which is more than 87 and it indicates they are affected by postpartum hemorrhage.

From the pulse rate of $\mathrm{P}$, we will initiate a fuzzy rule for identifying the postpartum hemorrhage affected patients in the form of Algorithm II.

\section{Algorithm II - Fuzzy Rules for Pulse Rate}

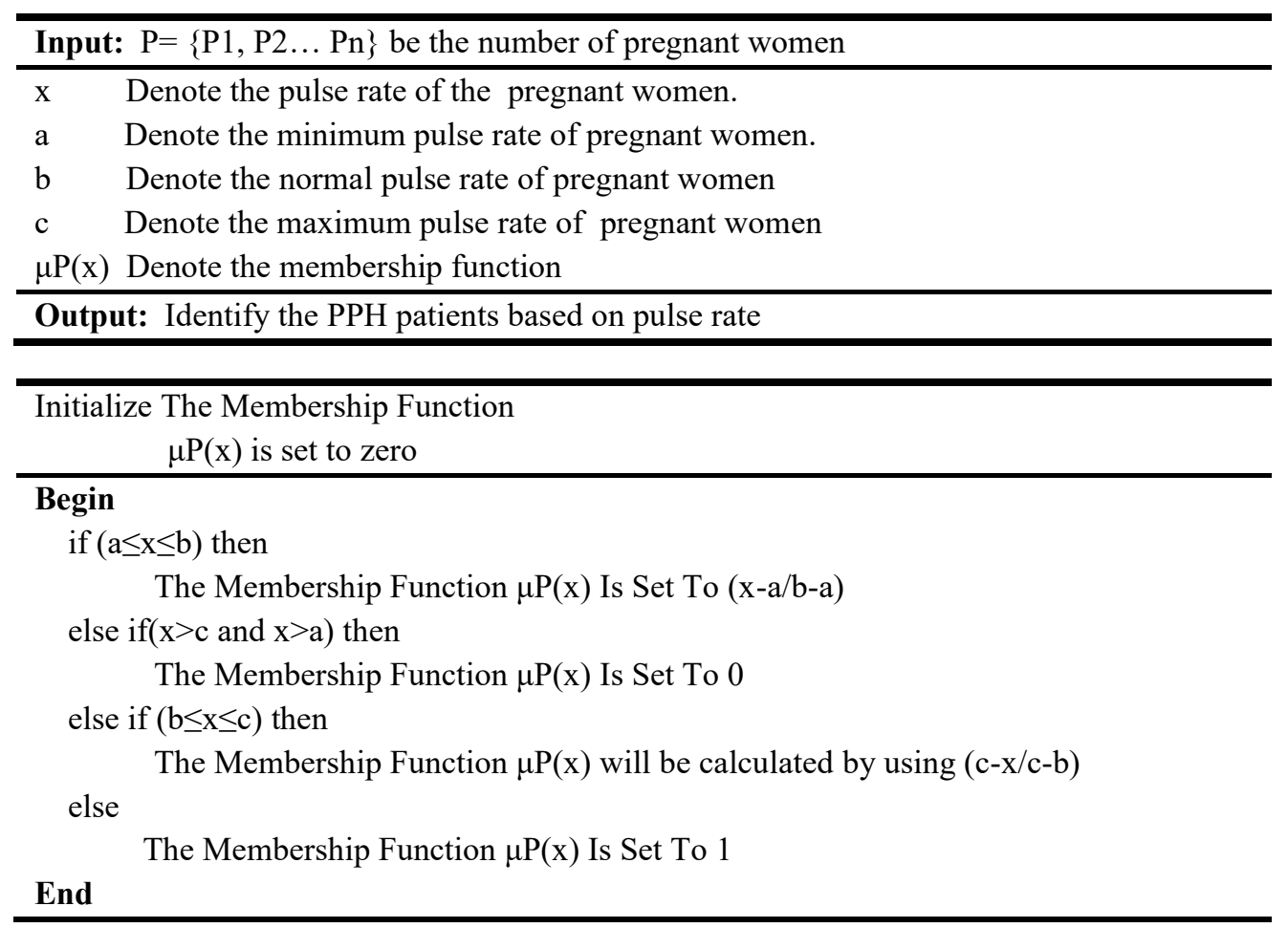




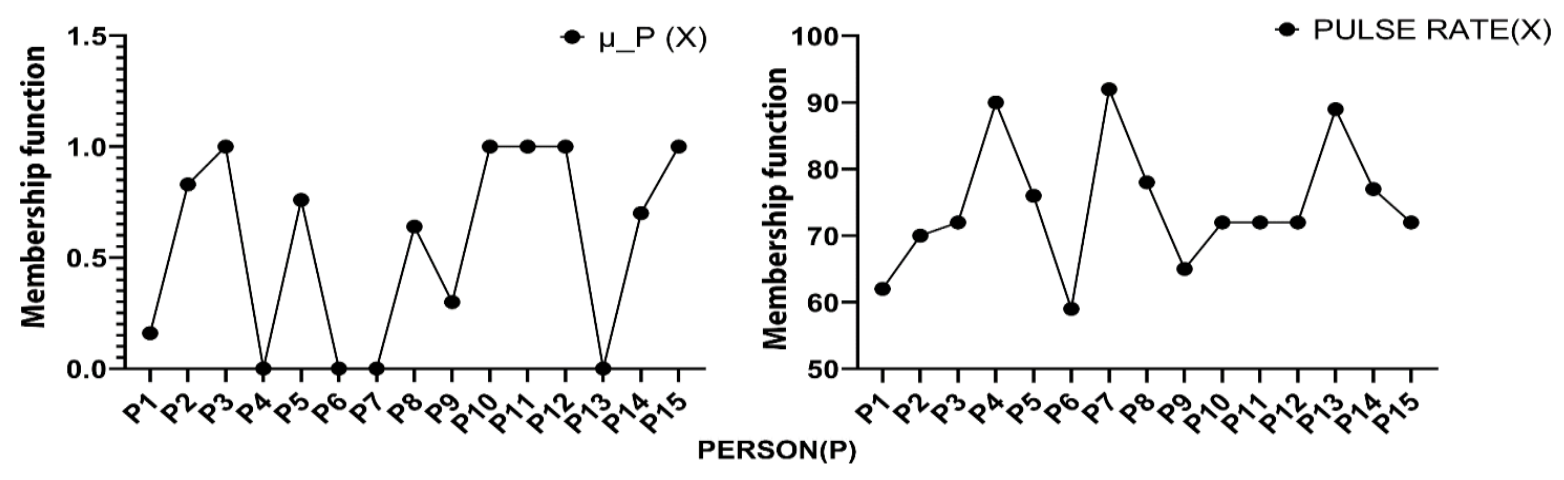

Fig. 6. Affected Patients List based on the Above Membership Function

As shown in Fig. 6, Persons P3, P10, P11, and P12 are not being affected by PPH because the value of their membership function for pulse rate is equal to 1 . However, P4, P6, P7, and P13 are being affected by PPH as the value of their membership function for pulse rate is equal to 0 . Further, remaining persons carrying membership function value for pulse rate between 0 and 1 are having tendency to fall in PPH and thus need medical assistance.

\subsection{Prediction of Blood Pressure using Fuzzy Series:}

The normal level of blood pressure is $120 / 80 \mathrm{~mm} / \mathrm{hg}$. If the blood pressure is higher than $140 / 90 \mathrm{~mm} / \mathrm{hg}$, then this condition indicates high blood pressure for pregnant women.

Membership Function for Blood Pressure: Let Bp be a fuzzy event whose membership function is $\mu_{\mathrm{Bp}}(\mathrm{x})$.For $\mu_{\mathrm{Bp}}(\mathrm{x}) \subseteq[0,1]$, so $\mu_{\mathrm{Bp}}(\mathrm{x})=1$, therefore a function exists $\mu_{\mathrm{Bp}}(\mathrm{x})$ which satisfies the equation 7 :

$$
\mu_{\mathrm{Bp}}(x)=\int_{\mathrm{b}}^{\mathrm{c}} \mathrm{f} \mu_{\mathrm{Bp}}(x) d x=1
$$

To identify the PPH patients, we should define the membership function $\mu_{\mathrm{Bp}}(\mathrm{X})$ satisfying equation 8 and as shown in Fig. 8.

$$
\mu_{\mathrm{Bp}}(\mathrm{x})=\int_{2}^{b_{\mathrm{x}-\mathrm{z}}} \frac{\mathrm{b}-\mathrm{z}}{\mathrm{d}}+\frac{\mathrm{d}-\mathrm{x}}{\mathrm{d}-\mathrm{c}}
$$

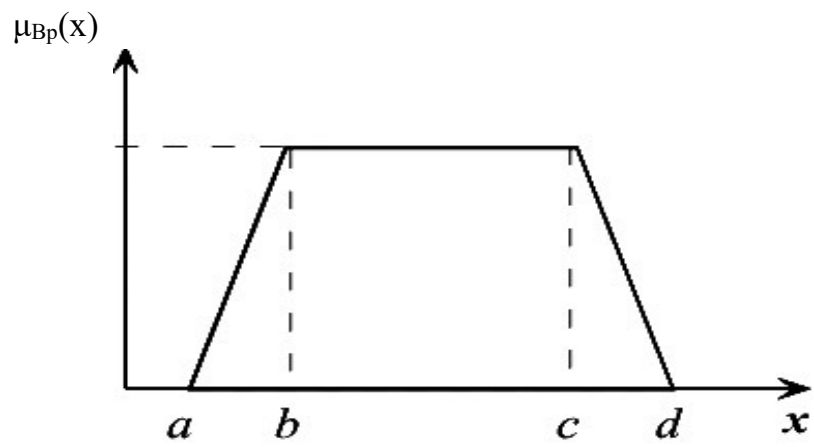

Fig. 7. Membership Function for Blood Pressure 
The membership function of pregnant women is defined by equation 9 as:

$$
\mu_{B p}(X)=\left\{\begin{array}{ccc}
\sum_{a}^{b} \frac{\mathrm{x}-\mathrm{x}}{\mathrm{b}-\mathrm{x}}+\sum_{c}^{d} \frac{\mathrm{d}-\mathrm{x}}{\mathrm{d}-\mathrm{c}} & , a \leq x \leq b \text { and } c \leq x \leq d \\
& 1 & , \boldsymbol{b} \leq \boldsymbol{x} \leq \mathrm{d} \\
& 0 & , \mathrm{x} \geq \mathrm{d}
\end{array}\right.
$$

where, $\quad \mathrm{P}=\{\mathrm{P} 1, \mathrm{P} 2 \ldots \mathrm{Pn}\}$ indicates the number of pregnant women.

$\mathrm{x}=\{\mathrm{x} 1, \mathrm{x} 2 \ldots \mathrm{xn}\}$ be the blood pressures of $\mathrm{N}$ number of patients

"a " indicates the minimum blood pressure of pregnant women which is less than $60 \mathrm{~mm} / \mathrm{hg}$

"b " denotes the starting pressure level of normal human body which is in $80 \mathrm{~mm} / \mathrm{hg}$ and it indicates the patient's health condition is normal.

"c" denotes the ending pressure level of normal human body which is in $120 \mathrm{~mm} / \mathrm{hg}$ and it also indicates that patient's health condition is normal.

"d" denotes the maximum blood pressure of the pregnant women which is more than $140 \mathrm{~mm} / \mathrm{hg}$ and it indicates that pregnant women are affected by PPH.

If the blood pressure of Pregnant women is in the range of $60-80 \mathrm{~mm} / \mathrm{hg}$ or $120 \mathrm{~mm} / \mathrm{hg}$ which is abnormal level, then we need to identify whether they are affected by PPH or not. From the blood pressure of P, we will initiate fuzzy rule for identifying the PPH affected patients in the form of Algorithm III.

\section{Algorithm - III Fuzzy Rule for Blood Pressure:}

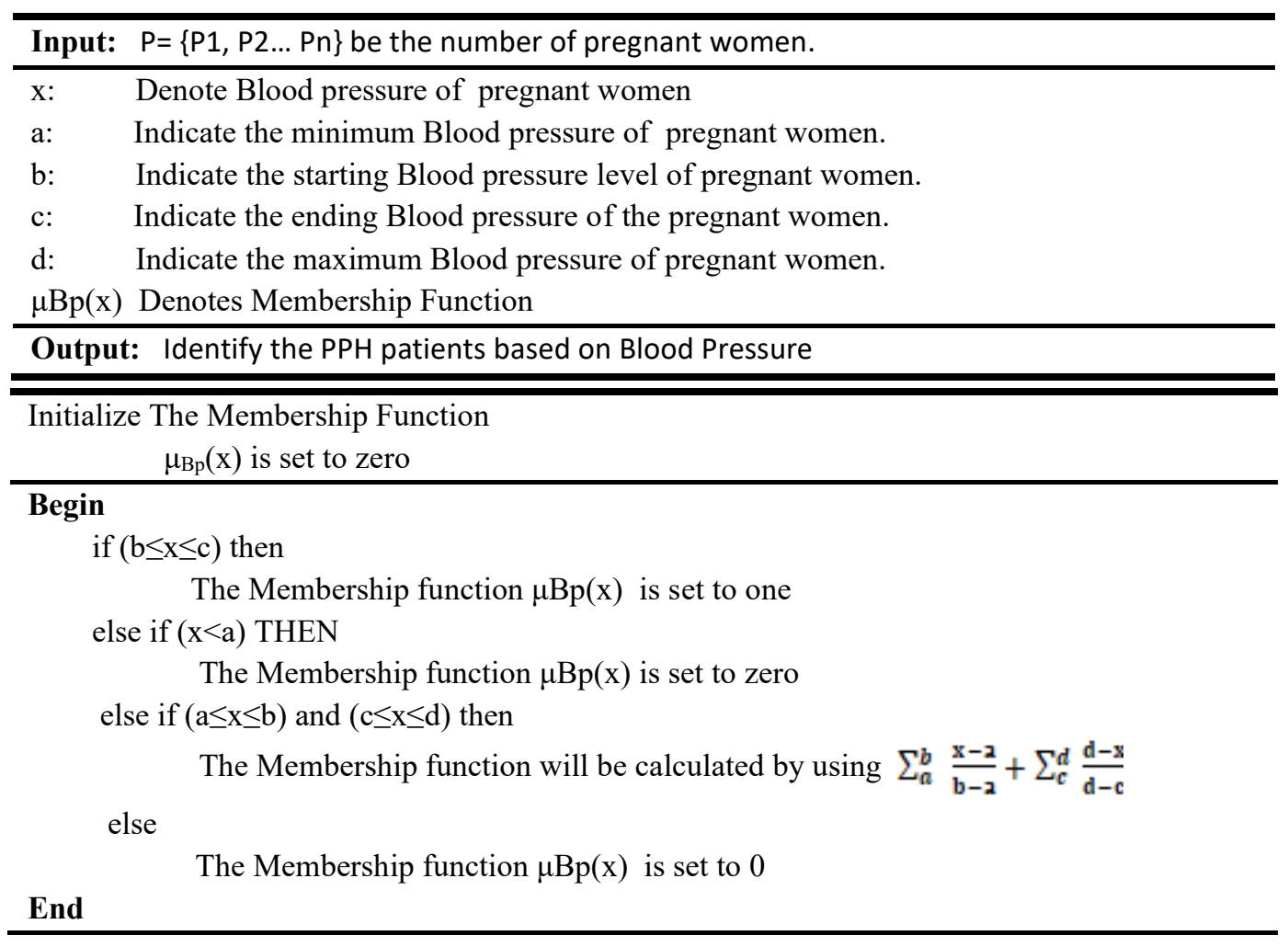




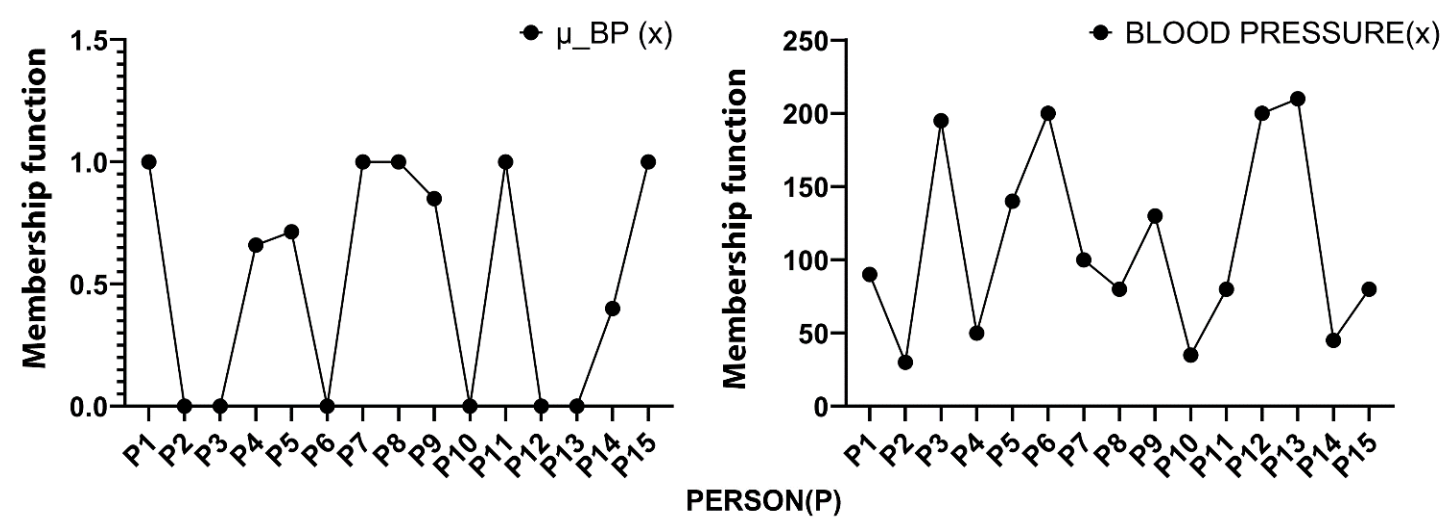

Fig. 8. Affected Patients List based on the above Membership Function

As shown in Fig. 8, Persons P1, P7, P8, P11, and P15 are not being affected by PPH because the value of their membership function for blood pressure is equal to 1 . However, P2, P3, 10, and P12 are being affected by PPH as the value of their membership function for blood pressure is equal to 0. Further, remaining persons carrying membership function value for blood pressure between 0 and 1 are having tendency to fall in PPH and thus need medical assistance.

\subsection{Prediction of Sweat Rate using Fuzzy Series:}

For an average person, the sweat gland rate is 0.8 to 1.4 liters per hour. Excessive sweating indicates underlying health condition which will affect pregnant women during childbirth.

Membership Function for Sweat Rate: Let $\mathrm{S}$ be a fuzzy event whose membership function is $\mu_{\mathrm{S}}(\mathrm{x})$. For $\mu_{\mathrm{S}}(\mathrm{x}) \subseteq$ $[0,1]$, so $\mu_{\mathrm{S}}(\mathrm{x})=1$, therefore a function exists $\mu_{\mathrm{S}}(\mathrm{x})$ which satisfies the equation 10 :

$$
\mu_{s}(x)=\int_{b}^{c} f \mu_{s}(x) d x=1
$$

To identify the PPH patients, we should define the membership function $\mu_{S}(x)$ satisfying equation 11 and as shown in Fig.9

$$
\mu_{s}(x)=\int_{2}^{b} \frac{x-z}{b-z}+\int_{c}^{d} \frac{d-x}{d-c}
$$

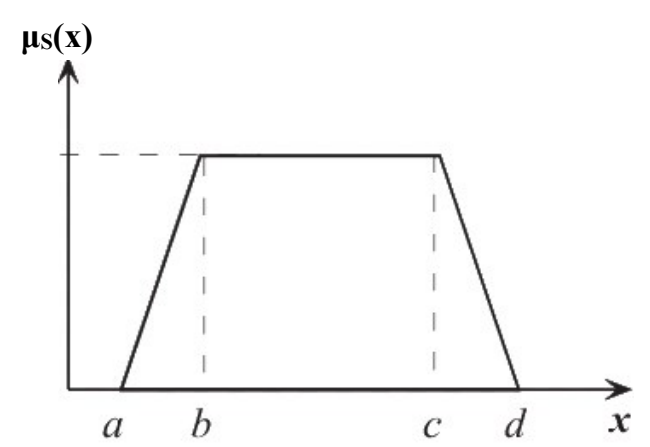

Fig. 9. Membership Function for Sweat Rate 
The membership function of pregnant women $(\mathrm{P})$ is defined in equation 12 as:

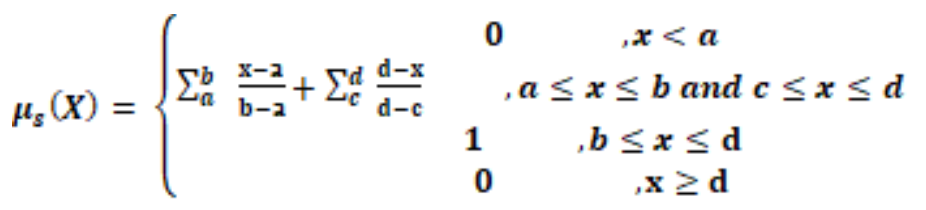

where, $\mathrm{P}=\{\mathrm{P} 1, \mathrm{P} 2 \ldots \mathrm{Pn}\}$ indicates the number of pregnant women.

$x=\{\mathrm{x} 1, \mathrm{x} 2 \ldots \mathrm{xn}\}$ be the sweat rates of $\mathrm{N}$ number of patients (i.e.) $\mathrm{x} \in \mathrm{P}$

" $a$ " indicates the minimum sweat rate of pregnant women which is less than 0.1 liters per hour

" $b$ " denotes the starting rate of normal human body which is 0.8 liters per hour and it indicates the patient's health condition is normal.

"c "denotes the ending rate of normal human body which is 1.4 liters per hour and it indicates that patient's health condition is normal.

" $d$ "denotes the maximum sweat rate of the pregnant women which is 4 liters per hour and it indicates that pregnant women are affected by PPH.

If the sweat rate of pregnant women is in the range of 0.1 to 0.8 or $1.4-4.0$ liters per hour, then it represents the abnormal level. In these conditions, we need to identify whether are affected by PPH or not.

From the sweat rate of P, we will initiate fuzzy rule for identifying the PPH affected patients in the form of Algorithm IV.

\section{Algorithm- IV Fuzzy Rule for Sweat Rate}

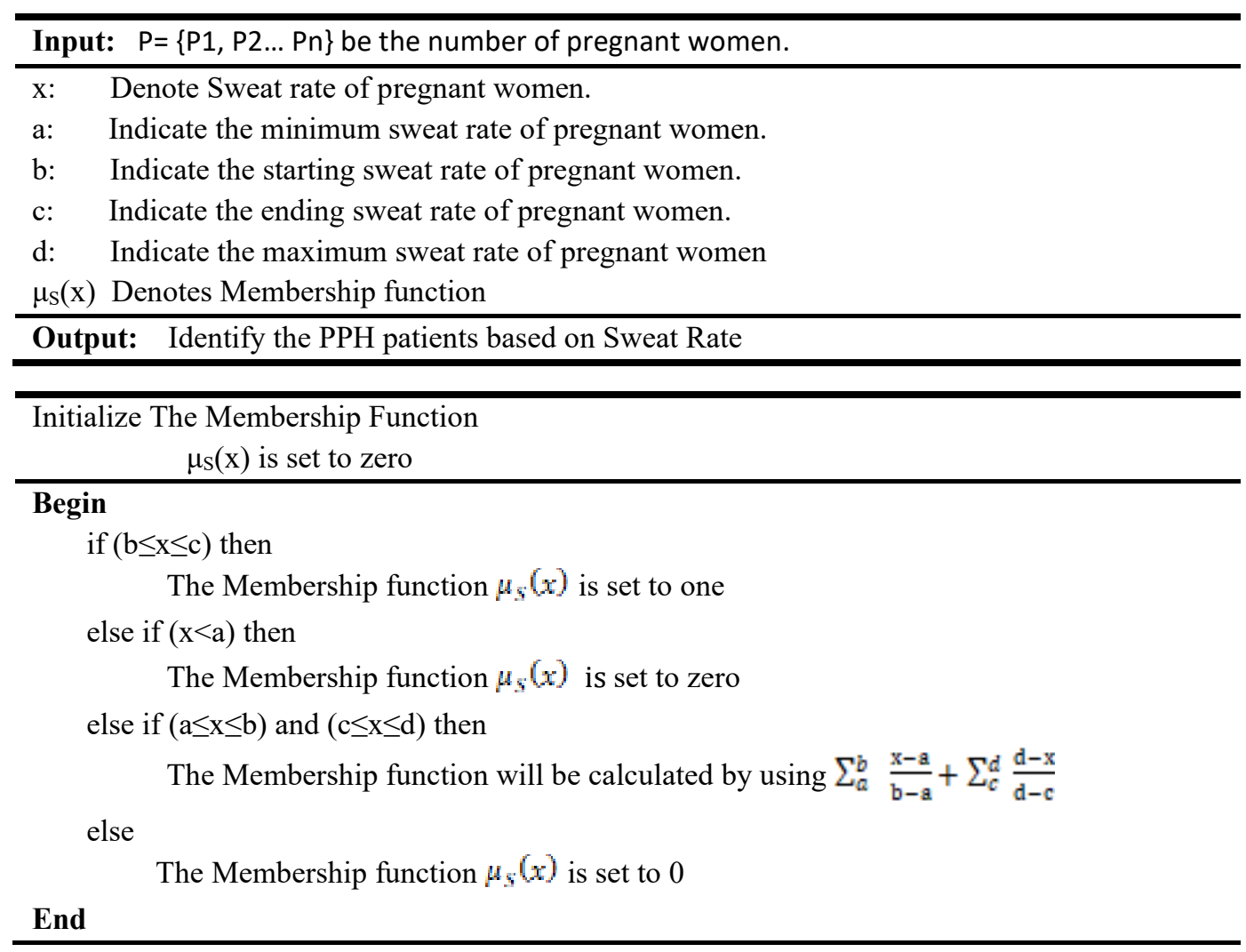




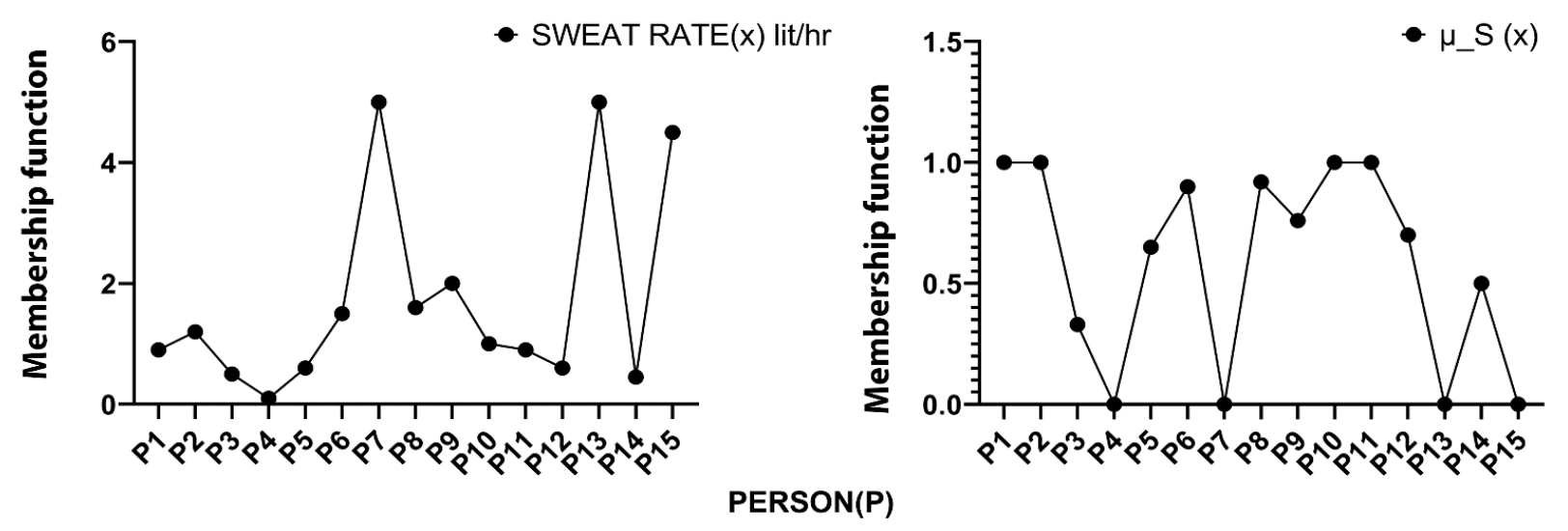

Fig. 10. Affected Patients List based on the above Membership Function

As shown in Fig. 10, Persons P2, P10, and P11 are not being affected by PPH because the value of their membership function for sweat rate is equal to 1 . However, P4, P7, P10, P13, and P15 are being affected by PPH as the value of their membership function for sweat rate is equal to 0 . Further, remaining persons carrying membership function value for sweat rate between 0 and 1 are having tendency to fall in PPH and thus need medical assistance.

These modules will be performed in the self-perspective neural network to predict the health conditions of pregnant women as shown in Fig.11.

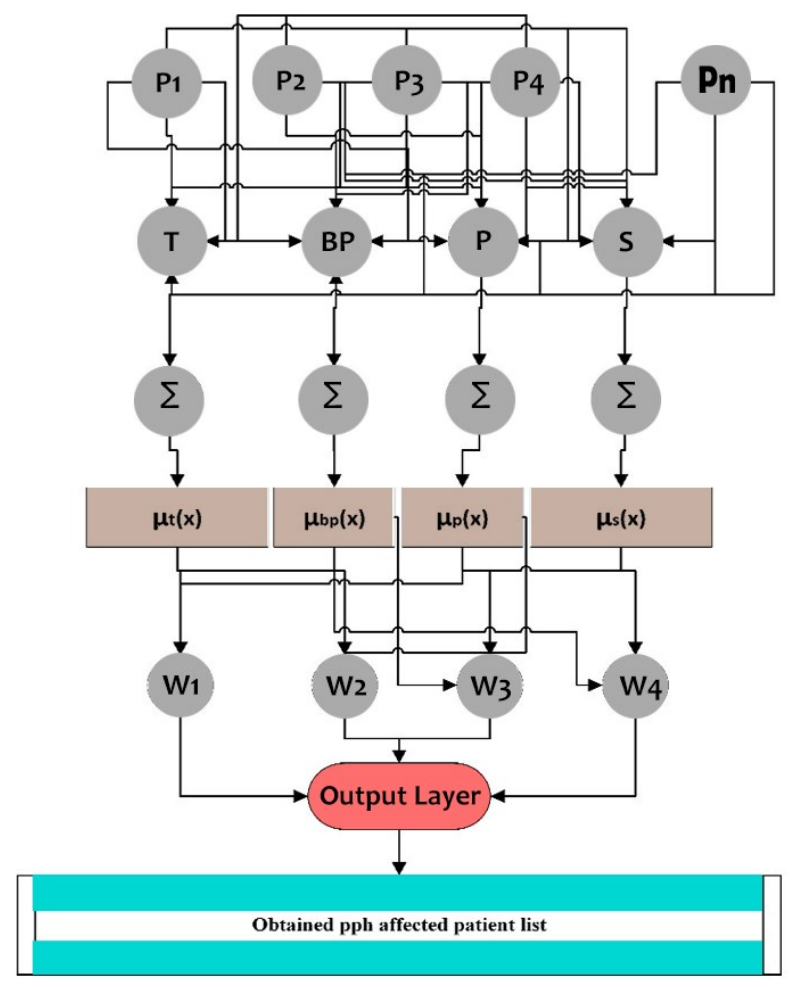

Fig. 11. Proposed Neural Network for Identifying the PPH Patients 


\subsection{Self-Perspective Neural Network}

PPH is the loss of blood in excess of $500 \mathrm{ml}$ during vaginal deliveries or caesarian deliveries. The result of PPH will increase the morbidity and mortality rate. For addressing these issues, a new proposed method is introduced for identifying the PPH affected patients.

Each neuron in the input layer represents the number of pregnant women (i.e) \{p1, p2, p3......pn\}.This layer feeds the input of patients parameter to the pattern layer. The pattern layer contains neuron for each parameter in the training datasets and stores their parameter details. For the given parameter, summation layer feeds the input to the next layer and then calculates membership function. The output layer compares the level of parameters with the normal ranges. If it exceeds, then the patients are affected by PPH and thus we will be in a position to obtain the PPH affected patient list. The FNT_PPH (Fuzzy Neural Technique_PPH) algorithm is designed to prevent the PPH affected patients and also used to intimate the doctor about the critical parameters level of pregnant women. The steps of FNT_PPH are explained in Algorithm-V.

\section{Algorithm-V FNT_PPH (Fuzzy Neural Technique_PPH) algorithm}

\begin{tabular}{l} 
Input: $\quad$ Let $\mathrm{T}=\{\mathrm{t} 1, \mathrm{t} 2 \ldots . ., \mathrm{t} n\}$ be the temperature of pregnant women \\
\hline $\mathrm{B} p=\{\mathrm{b} 1, \mathrm{~b} 2 . ., \mathrm{bn}\}$ be the Blood pressure of pregnant women \\
$\mathrm{P}=\quad\{\mathrm{p} 1, \mathrm{p} 2 \ldots ., \mathrm{pn}\}$ be the pulse rate of pregnant women \\
$\mathrm{S}=\quad\{\mathrm{s} 1, \mathrm{~s} 2 \ldots, \mathrm{sn}\}$ be the sweat rate of pregnant women \\
$\mathrm{P}=\quad\{\mathrm{p} 1, \mathrm{p} 2 \ldots, \mathrm{pn}\}$ be the number of persons \\
\hline Output: Print the list of $\mathrm{PPH}$ affected patients and their parameters.
\end{tabular}

\subsection{Alerting System through IoT}

ZigBee (IEEE 802.15.4) technology is used for the intimation process. It is a low rate-level communication protocol used to create a Wireless Personal Area Network (WPAN) for various applications like home automation, medical data collection, weather information collection, and many more. It may also be used an alerting system through IoT. For the parameter level of the pregnant women, this technology will be used to generate an alert message to medical practitioner whose availability is in nearby location.

\section{Experimental Test and Results}

For conducting experiment and applying all fuzzy rules, the data has been collected from Panimalar Health care Hospital, Chennai, India. The data contains temperature, pressure, pulse rate and sweat rate of pregnant women. It comprises of 130 patient samples post-pregnancy. Each sample represents the parameter and their biological conditions.

\subsection{Indicator Definition of PPH Performance:}

The membership function of each patient is used to evaluate the performance. The metrics used in this method are $\mathrm{H}_{\mathrm{PPH}}$ (High Level Postpartum Haemorrhage), N NPH (Normal Level Postpartum Haemorrhage), $\mathrm{M}_{\mathrm{PPH}}$ (Medium Level Postpartum Haemorrhage). Table 1 shows the membership function of pregnant women based on their parameter level. Membership function value of 1 indicates patient state with $\mathrm{N}_{\mathrm{PPH}}, 0$ indicates patient state with $\mathrm{H}_{\mathrm{PPH}}$ and values in between 0 to 1 indicate $\mathrm{M}_{\mathrm{PPH}}$. The membership function of all parameters is given in Table 1. 
Table 1. Membership Function of all Parameters

\begin{tabular}{|l|l|l|l|l|}
\hline Person (P) & $\begin{array}{l}\text { Temperature } \\
(\boldsymbol{\mu} \mathbf{T}(\mathbf{x}))\end{array}$ & $\begin{array}{l}\text { Pulse } \\
\text { rate }(\boldsymbol{\mu} \mathbf{P}(\mathbf{x}))\end{array}$ & $\begin{array}{l}\text { Blood } \\
\text { Pressure(} \boldsymbol{\mu}_{\mathbf{B p}}(\mathbf{x})\end{array}$ & $\begin{array}{l}\text { Sweat rate( } \\
\boldsymbol{\mu}_{\mathbf{S}}(\mathbf{x})\end{array}$ \\
\hline P1 & 0 & 0.16 & 1 & 1 \\
\hline P2 & 0.66 & 0.83 & 0 & 1 \\
\hline P3 & 0.629 & 1 & 0 & 0.33 \\
\hline P4 & 0.77 & 0 & 0.66 & 0 \\
\hline P5 & 0.88 & 0.76 & 0.714 & 0.65 \\
\hline P6 & 1 & 0 & 0 & 0.9 \\
\hline P7 & 0.55 & 0 & 1 & 0 \\
\hline P8 & 0.22 & 0.64 & 1 & 0.92 \\
\hline P9 & 0.33 & 0.3 & 0.85 & 0.76 \\
\hline P10 & 1 & 1 & 0 & 1 \\
\hline P11 & 1 & 1 & 1 & 0.7 \\
\hline P12 & 0.8 & 1 & 0 & 0 \\
\hline P13 & 0 & 0 & 0 & 0.5 \\
\hline P14 & 0.6 & 0.7 & 0.4 & 0 \\
\hline P15 & 1 & 1 & 1 & \\
\hline
\end{tabular}

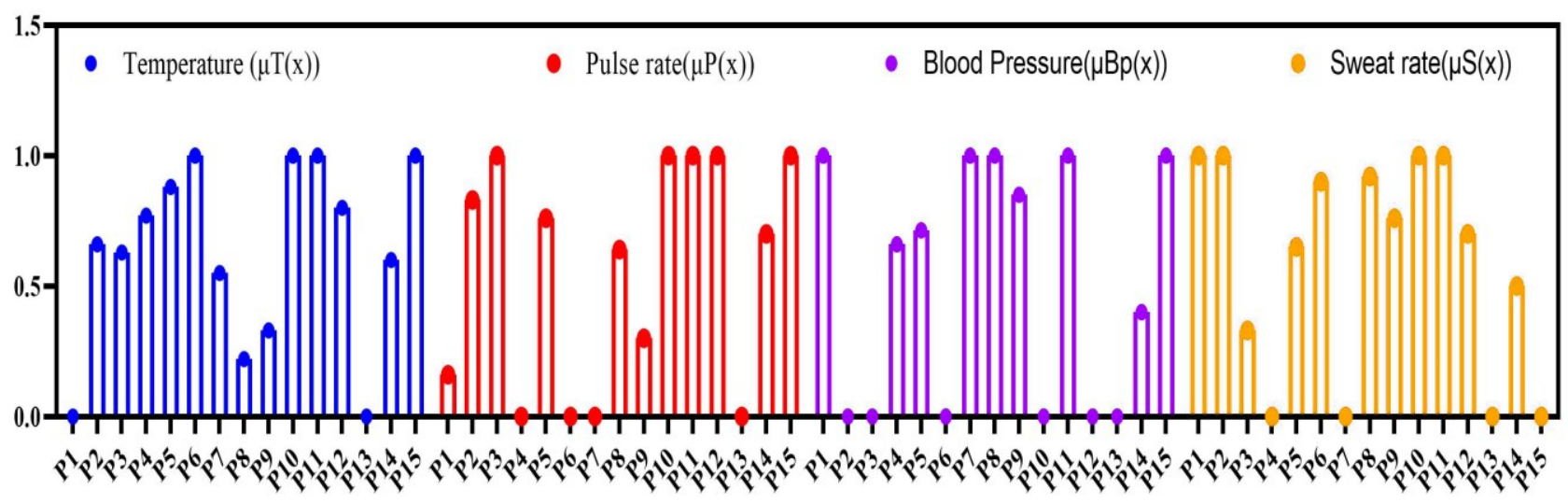

Person Identification

Fig. 12. Affected Patients List based on the Membership Functions

As shown in Fig. 12, P11 is not affected by PPH because the value of their membership function for all parameters is equal to 1 . However, P13 is affected by PPH as the value of their membership function for all parameters is equal to 0 . Further, remaining persons carrying membership function value for all parameters between 0 and 1 are having tendency to fall in PPH and thus need medical assistance.

From the Table 5, the metrics given in equations 5, 6 and 7 are used to find the accuracy of affected patient list after maternity period. 


$$
\mathrm{H}_{\mathrm{PPH}}=\frac{\text { probability of } 0 \text { occurrences among the parameter of them }}{\text { Total number of membership function (all possible parameter) }}
$$

$$
\mathrm{N}_{\mathrm{PPH}=}=\frac{\text { probability of } 1 \text { occurrences among the parameter of them }}{\text { Total number of membership function (all possible parameter) }}
$$

$$
\mathrm{M}_{\mathrm{PPH}}=\frac{\text { Maximum number of non negative values }}{\text { Total number of membership function (all possible parameter) }}
$$

The accuracy of $\mathrm{H}_{\mathrm{PPH}}, \mathrm{N}_{\mathrm{PPH}}$, and $\mathrm{M}_{\mathrm{PPH}}$ are calculated by using equations 5, 6, and 7 respectively and their calculated values are listed in Table 2 and shown in Fig. 13.

Table 2. Accuracy of PPH

\begin{tabular}{|c|c|}
\hline Metrics & Accuracy \\
\hline $\mathrm{H}_{\mathrm{PPH}}$ & $25 \%$ \\
\hline $\mathrm{N}_{\mathrm{PPH}}$ & $50 \%$ \\
\hline $\mathrm{M}_{\mathrm{PPH}}$ & $25 \%$ \\
\hline
\end{tabular}

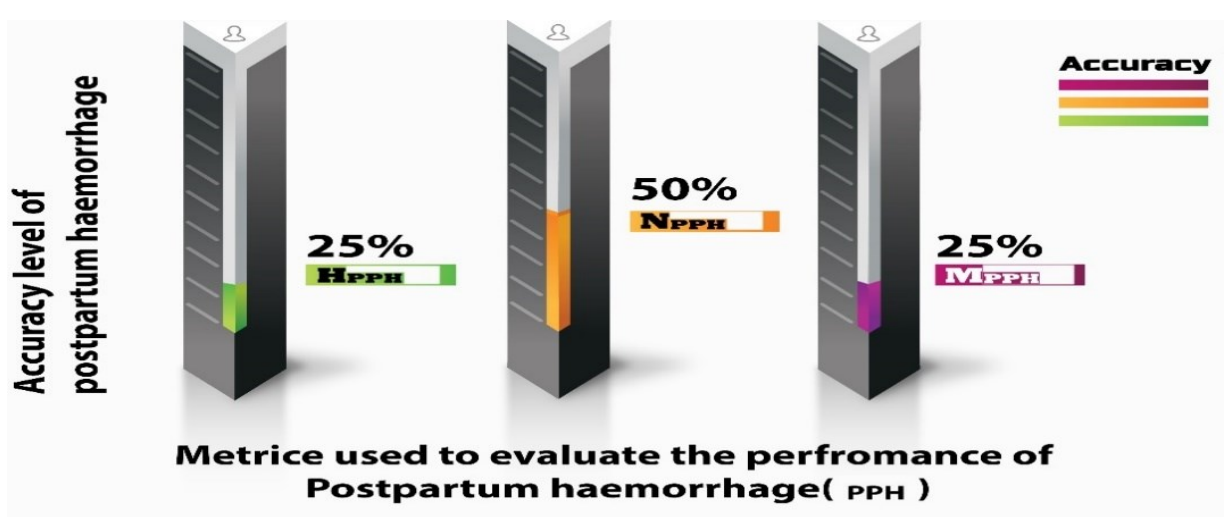

Fig. 13. Obtained Accuracy Level of PPH

\section{Conclusion}

In this paper, we have analyzed several parameters of patients that are very useful in fuzzy neural techniques (FNT_PPH) for predicting the PPH affected patients. An automation system for preventing PPH has been developed with the use of wearable devices. Our developed system measured the parameters of temperature, pulse, blood pressure, and sweat rate of pregnant women. Based on these measured values, if the condition of abnormality is satisfied in this system, then predicted values will be sent to the doctor or nurse in nearby locations through IoT that will help pregnant women to get medical attention and thus prevented from PPH after maternity. The authors believe that this developed system will help medical sciences in reducing the mortality and morbidity rate among pregnant women. 


\section{Acknowledgement}

This research was supported by Researchers Supporting Project Number (RSP-2020/250), King Saud University, Riyadh, Saudi Arabia.

\section{Conflict of Interest}

The authors have no conflict to declare.

\section{References}

[1] Wetta, L. A., Szychowski, J. M., Seals, S., Mancuso, M. S., Biggio, J. R., \& Tita, A. T. (2013). Risk factors for uterine atony/postpartum hemorrhage requiring treatment after vaginal delivery. American journal of obstetrics and gynecology, 209(1), 51-e1.

[2] Bateman, B. T., Berman, M. F., Riley, L. E., \& Leffert, L. R. (2010). The epidemiology of postpartum hemorrhage in a large, nationwide sample of deliveries. Anesthesia \& Analgesia, 110(5), 1368-1373.

[3] Knight, M., Callaghan, W. M., Berg, C., Alexander, S., Bouvier-Colle, M. H., Ford, J. B. \& Oats, J. (2009). Trends in postpartum hemorrhage in high resource countries: a review and recommendations from the International Postpartum Hemorrhage Collaborative Group. BMC pregnancy and childbirth, 9(1), 1-10.

[4] Sultan, S., Javed, A., Irtaza, A., Dawood, H., Dawood, H., \& Bashir, A. K. (2019). A hybrid egocentric video summarization method to improve the healthcare for Alzheimer patients. Journal of Ambient Intelligence and Humanized Computing, 10(10), 4197-4206.

[5] Rouse, D. J. (2013). What is new in postpartum hemorrhage: best articles from the past year. Obstetrics \& Gynecology, 122(3), 693-694.

[6] Rani, P. R., \& Begum, J. (2017). Recent advances in the management of major postpartum haemorrhage-a review. Journal of clinical and diagnostic research: JCDR, 11(2), QE01.

[7] World Health Organization, \& Safe Motherhood Initiative. (1990). The Prevention and management of postpartum haemorrhage: report of a technical working group, Geneva, 3-6 July, 1989 (No. WHO/MCH/90.7. Unpublished). World Health Organization.

[8] Edhi, M. M., Aslam, H. M., Naqvi, Z., \& Hashmi, H. (2013). Post-partum hemorrhage: causes and management. BMC research notes, 6(1), 236.

[9] Sharma, D., Singh Aujla, G., \& Bajaj, R. (2020). Deep neuro-fuzzy approach for risk and severity prediction using recommendation systems in connected health care. Transactions on Emerging Telecommunications Technologies, e4159.

[10] Rani, P. R., \& Begum, J. (2017). Recent advances in the management of major postpartum haemorrhage-a review. Journal of clinical and diagnostic research: JCDR, 11(2), QE01.

[11] Dildy Iii, G. A. (2002). Postpartum hemorrhage: new management options. Clinical obstetrics and gynecology, 45(2), 330-344.

[12] Sachs, J., Freedman, L. P., \& Waldman, R. (2005). Who's got the power? Transforming health systems for women and children (Vol. 5). Earthscan.

[13] Mousa, H. A., Blum, J., Abou El Senoun, G., Shakur, H., \& Alfirevic, Z. (2014). Treatment for primary postpartum haemorrhage. Cochrane database of systematic reviews, (2).

[14] Mousa, H. A., \& Alfirevic, Z. (2014). Treatment for primary postpartum haemorrhage (Review). Cochrane Library.

[15] Reynders, F. C., Senten, L., Tjalma, W., \& Jacquemyn, Y. (2006). Postpartum hemorrhage: practical approach to a life-threatening complication. Clin Exp Obstet Gynecol, 33(2), 81-4.

[16] Chandraharan, E., \& Krishna, A. (2017). Diagnosis and management of postpartum haemorrhage. Bmj, 358.

[17] Pavord, S., \& Maybury, H. (2015). How I treat postpartum hemorrhage. Blood, 125(18), 2759-2770.

[18] Kominiarek, M. A., \& Kilpatrick, S. J. (2007, June). Postpartum hemorrhage: a recurring pregnancy complication. In Seminars in perinatology (Vol. 31, No. 3, pp. 159-166). WB Saunders.

[19] Sharma, S., Dudeja, R. K., Aujla, G. S., Bali, R. S., \& Kumar, N. (2020). DeTrAs: deep learning-based healthcare framework for IoT-based assistance of Alzheimer patients. Neural Computing and Applications, 1-13.

[20] Su, C. W. (2012). Postpartum hemorrhage. Primary Care: Clinics in Office Practice, 39(1), $167-187$. 
[21] Diop, A., Abbas, D., Ngoc, N., Martin, R., Razafi, A., Thi, H.,Winikoff, B. (2020). A double-blind, randomized controlled trial to explore oral tranexamic acid as adjunct for the treatment for postpartum hemorrhage. $1-7$.

[22] Sentilhes, L., Daniel, V., \& Deneux-Tharaux, C. (2020). TRAAP2-TRAnexamic Acid for preventing postpartum hemorrhage after cesarean delivery: A multicenter randomized, doubleblind, placebocontrolled trial- A study protocol. BMC Pregnancy and Childbirth, 20(1), 1-11. https://doi.org/10.1186/s12884-019-2718-4

[23] Punt, M. C., Schuitema, P. C. E., Bloemenkamp, K. W. M., Kremer Hovinga, I. C. L., \& van Galen, K. P. M. (2020). Menstrual and obstetrical bleeding in women with inherited platelet receptor defects-A systematic review. Haemophilia, (October 2019), 216-227. https://doi.org/10.1111/hae.13927

[24] Nyfløt, L. T., Sandven, I., Stray-Pedersen, B., Pettersen, S., Al-Zirqi, I., Rosenberg, M., \& Vangen, S. (2017). Risk factors for severe postpartum hemorrhage: a case-control study. BMC pregnancy and childbirth, 17(1), 17.

[25] Feduniw, S., Warzecha, D., Szymusik, I., \& Wielgos, M. (2020). Epidemiology, prevention and management of early postpartum hemorrhage - a systematic review. Ginekologia Polska, 91(1), 45-51.

[26] Saha, A., \& Das, M. (2017, December). Impact of social networking sites on post-partum depression in women: An analysis in the context of Bangladesh. In 2017 20th International Conference of Computer and Information Technology (ICCIT) (pp. 1-6). IEEE.

[27] Qi, F., Tian, D., Wang, Y., \& Jiao, L. (2018, October). Prediction of Postpartum Hemorrhage by Adaptive K-Nearest Neighbor Based on Influence Factors. In 2018 9th International Conference on Information Technology in Medicine and Education (ITME) (pp. 904-910). IEEE.

[28] Purwahana, R., Suryono, S., \& Suseno, J. E. (2018, October). Cloud-Based Multinomial Logistic Regression for Analyzing Maternal Mortality Data in Postpartum Period. In 2018 2nd International Conference on Informatics and Computational Sciences (ICICoS) (pp. 1-4). IEEE.

[29] Surbek, D., Vial, Y., Girard, T., Breymann, C., Bencaiova, G. A., Baud, D., \& Hösli, I. (2020). Patient blood management (PBM) in pregnancy and childbirth: literature review and expert opinion. Archives of gynecology and obstetrics, 301(2), 627-641.

[30] Adegoke, O., Danso-Bamfo, S., Sheehy, M., Tarimo, V., Burke, T. F., \& Garg, L. F. (2020). A condom uterine balloon device among referral facilities in Dar Es Salaam: An assessment of perceptions, barriers and facilitators one year after implementation. BMC Pregnancy and Childbirth, 20(1), 1-6.

[31] Mollazadeh-Moghaddam, K., Dundek, M., Bellare, A., Borovac-Pinheiro, A., Won, A., \& Burke, T. (2020). Mechanical properties of ESM-UBT: An ultra-low cost uterine balloon tamponade device. 2019 IEEE Global Humanitarian Technology Conference (GHTC), 1-2.

[32] Alalfy, M., Lasheen, Y., Elshenoufy, H., Elzahaby, I. M., Kaleem, H. W., El Sawah, H., Rashwan, A. S. S. A. (2020). The efficacy of intrauterine misoprostol during cesarean section in prevention of primary PPH, a randomized controlled trial. Journal of Maternal-Fetal and Neonatal Medicine, 33(9), 14591465 .

[33] Weeks, A. (2015). The prevention and treatment of postpartum haemorrhage: what do we know, and where do we go to next? BJOG: An International Journal of Obstetrics \& Gynaecology, 122(2), $202-$ 210.

[34] El-Refaey, H., \& Rodeck, C. (2003). Post-partum haemorrhage: definitions, medical and surgical management. A time for change. British medical bulletin, 67(1), 205-217.

[35] Aflaifel, N. B., Chandhiok, N., Fawole, B., Geller, S. E., \& Weeks, A. D. (2019). Use of histograms to assess the efficacy of uterotonic treatment for post-partum haemorrhage: A feasibility study. Best Practice \& Research Clinical Obstetrics \& Gynaecology, 61, 15-27.

[36] Tsafack, N., Sankar, S., Abd-El-Atty, B., Kengne, J., Jithin, K. C., Belazi, A, Abd El-Latif, A. A. (2020). A new chaotic map with dynamic analysis and encryption application in Internet of Health Things. IEEE Access, 8, 137731-137744.

[37] Salamah, U., Kartikawangi, S., \& Suryani, E. (2019). Identification of Postpartum Infection Type using Mamdani Fuzzy System. Proceedings of 2019 4th International Conference on Informatics and Computing, ICIC 2019.

[38] Zeni Montenegro, J. L., Andre Da Costa, C., Da Rosa Righi, R., Roehrs, A., \& Farias, E. R. (2018). A proposal for postpartum support based on natural language generation model. Proceedings - 2018 International Conference on Computational Science and Computational Intelligence, CSCI 2018, 756759. 
[39] Iyawa, G. E., \& Hamunyela, S. (2019). MHealth Apps and Services for Maternal Healthcare in Developing Countries. 2019 IST-Africa Week Conference, IST-Africa 2019, 1-10. 